\title{
A simple model for closure temperature of a trace element in cooling bi-mineralic systems
}

\author{
Yan Liang \\ Department of Earth, Environmental and Planetary Sciences \\ Brown University, Providence, Rhode Island 02912 \\ Email: Yan_Liang@brown.edu_Phone: 401-863-9477
}

\begin{abstract}
Closure temperature is defined as the lower temperature limit at which the element of interest effectively ceases diffusive exchange with its surrounding medium during cooling. Here we generalize the classic equation of Dodson (1973) for cooling mono-mineralic systems to cooling bi-mineralic aggregates by considering diffusive exchange of a trace element between the two minerals in a closed system. We present a simple analytical model that includes key parameters affecting the closure temperature of a trace element in cooling bi-mineralic systems: cooling rate, temperature-dependent diffusion coefficients for the trace element in the two minerals, temperature-dependent partition coefficient of the trace element between the two minerals, effective grain sizes of the two minerals, and volume proportions of the minerals in the system. We show that closure temperatures of a trace element in cooling bi-mineralic systems are bounded by the closure temperatures of the trace element in the two mono-mineralic systems and that our generalized model reduces to Dodson's equation when one of the mineral serves as "an effective infinite" reservoir to the other mineral. Application to closure temperatures of REE in orthopyroxene and clinopyroxene bi-mineralic systems highlights the importance of REE diffusion and partitioning in the pyroxenes as well as clinopyroxene modal abundance and grain size in the systems. Closure temperatures for REE in two-pyroxene bearing equigranular rocks are controlled primarily by diffusion in orthopyroxene unless the modal abundance of clinopyroxene is very small. This has important bearings on the interpretation of temperatures derived from the REE-in-two-pyroxene thermometer.
\end{abstract}




\section{1. INTRODUCTION}

3 Closure temperature is an important topic to many diffusion related problems involving

4 changes in temperature during the course of diffusive exchange between a mineral grain and its

5 surrounding medium (e.g., Crank, 1975; Albarède, 1995; Lasaga, 1998; Zhang, 2008). It is

6 defined as the lower temperature limit at which the element of interest effectively ceases

7 diffusive exchange with its surrounding medium during cooling. The original formulation of

8 closure temperature was rigorously derived by Dodson $(1973,1976,1983)$ for cooling mono-

9 mineralic systems by considering analytical solutions to diffusion equations with temperature- or

10 time-dependent diffusion coefficient. According to Dodson (1973), closure temperature $\left(T_{c}\right)$ for

11 an element in a mineral grain depends on diffusion parameters of the element and decreases with

12 the decrease of the product of cooling rate and the square of effective diffusion radius $\left(d_{A}\right)$. It is

13 given by Dodson's equation

14

$$
\frac{E_{A}}{R T_{c}}=G+\ln \frac{D_{A}^{0} R T_{c}^{2}}{E_{A} \dot{s} d_{A}^{2}},
$$

15 where $G$ is the closure function, depending on geometry of the system; $E_{A}$ and $D_{A}^{0}$ are the

16 activation energy and pre-exponential factor for diffusion of the element of interest; $\dot{s}$ is the

17 cooling rate at the closure temperature; and $R$ is the gas constant. Eq. 1a can also be written in

18 terms of the diffusion coefficient evaluated at the closure temperature, $D_{A}^{c}$, viz.,

$$
\frac{E_{A} \dot{s}}{R T_{c}^{2}} \frac{d_{A}^{2}}{D_{A}^{c}}=\exp (G),
$$

20 where terms on the left hand side of Eq. $1 \mathrm{~b}$ represent a measure of diffusion time relative to

21 cooling time at the closure temperature (see Section 2.1. below). The geometry function, $G$, in

22 Dodson's equation was modified by Ganguly and Tirone (1999) to include the "memory effect" 
1 that arises from situations when diffusion has not affected the center of the crystal (i.e., cases of

2 fast cooling and large grain size). Dodson's equation and its modification (e.g., Ganguly and

3 Tirone, 1999; Gardés and Montel, 2009; Watson and Cherniak, 2013) have been widely used to

4 study the closure temperature and thermal history of igneous and metamorphic rocks (e.g.,

5 Giletti, 1986; Ganguly et al., 2007).

6 Most petrologic systems are polycrystalline, consisting of more than one mineral. Closure

7 temperatures for bi-mineralic or poly-mineralic systems were investigated in a number of studies

8 through numerical simulations or analytical solutions of the diffusion equations (e.g., Lasaga et

9 al., 1977; Onorato et al., 1981; Lasaga, 1983; Spear, 1991; Eiler et al., 1992; Jenkin et al., 1994,

10 1995; Ehlers and Powell, 1994; Powell and White, 1995). Although significant progress has been

11 made in understanding closure temperature for cooling bi-mineralic systems through these

12 studies, algebraic equations for closure temperatures were either not available or obtained under

13 simplified settings. For example, the equation of Powell and White (1995) was obtained under

14 the assumption that cation diffusion in one mineral is significantly faster than that in the other

15 (see also Ehlers and Powell, 1994). Application of the equation of Powell and White (1995) to

16 REE in cooling diopside-enstatite systems leads to inconsistent results (Yao and Liang, in press)

17 as diffusion coefficients of light REE in diopside are smaller than those in enstatite, whereas

18 diffusion coefficients of heavy REE in diopside are larger than those in enstatite (Fig. 1a, Van

19 Orman et al., 2001; Cherniak and Liang, 2007; but see also Sano et al., 2011).

20 In general, diffusive re-equilibration of a trace element between two minerals in a closed

21 system depends on mineral-mineral trace element partition coefficient, diffusion coefficients for

22 the trace element in the two minerals, grain sizes of the two minerals, as well as volume

23 proportions of the minerals in the system (e.g., Lasaga et al., 1977; Lasaga, 1983; Liang, 2014). 
1 The main objective of this study is to quantify the relationships among the aforementioned

2 parameters for the closure temperature of a trace element in cooling bi-mineralic systems. A

3 simple algebraic expression will be very useful for assessing the relative roles of the various

4 parameters in controlling closure temperatures. As will be shown in this study, the closure

5 temperature of a trace element in cooling bi-mineralic system is bounded by the closure

6 temperatures of the trace element in the two mono-mineralic systems and that mineral-mineral

7 trace element partition coefficient and modal abundances are also important in determining

8 closure temperatures for the bi-mineralic systems.

\section{CLOSURE TEMPERATURE AND TIME SCALES FOR DIFFUSION AND COOLING}

11 We consider diffusive exchange of a trace element in a cooling bi-mineralic aggregate

12 consisting of minerals $\mathrm{A}$ and $\mathrm{B}$ of average half sizes or radii $d_{A}$ and $d_{B}$ and volume fractions $\phi_{A}$

13 and $\phi_{B}$, respectively, in a representative elementary volume or REV. For simplicity, we assume

14 that (1) diffusion in the minerals is isotropic; (2) the two minerals are in local equilibrium at their

15 interfaces; (3) grain boundary diffusion is much faster than volume diffusion in the two minerals,

16 so that mass exchanges freely along grain boundaries among minerals within the REV (e.g., Eiler

17 et al., 1992); and (4) grain growth is negligible during the course of diffusive exchange. The

18 temperature-dependent diffusion coefficients for the trace element of interest in the two minerals

19 take on the usual expressions:

$$
D_{A}(T)=D_{A}^{0} \exp \left(-\frac{E_{A}}{R T}\right),
$$

$$
D_{B}(T)=D_{B}^{0} \exp \left(-\frac{E_{B}}{R T}\right),
$$


1 where subscripts $\mathrm{A}$ and $\mathrm{B}$ refer to the two minerals. Assumption (2) allows us to relate

2 concentrations of a trace element at the surfaces of mineral A and mineral B through a mineral-

3 mineral partition coefficient, $k_{A B}$, which is a function of temperature, pressure, and mineral

4 compositions. For simplicity, we use the Arrhenius expression in the present study

$$
k_{A B}(T)=k_{A B}^{0} \exp \left(-\frac{E_{k}}{R T}\right),
$$

where $E_{k}$ and $k_{A B}^{0}$ are the exchange energy and pre-exponential factor for the partitioning of a

7 trace element between mineral A and mineral B. Physically, $E_{k}$ is a sum of two parts: (1) the

8 change in internal energy for strain-free exchange of the trace element of interest between

9 mineral A and mineral B, and (2) the difference in lattice strain energy for the substitution of the

10 trace element in the two minerals (see Eq. 2 in Sun and Liang, 2014).

11 Standard analysis of closure temperature in cooling mono-mineralic or bi-mineralic systems

12 involves analytical or numerical solutions of diffusion equations subject to prescribed cooling.

13 Although the governing diffusion equations and the initial and boundary conditions for the bi-

14 mineralic system are well known (e.g., Lasaga et al., 1977; Onorato et al., 1981; Eiler et al.,

15 1992; Ehlers and Powell, 1994), their mathematical analyses are considerably more difficult

16 without further simplification (e.g., Powell and White, 1995). To include all the key features of

17 the closure temperature for the cooling bi-mineralic system, here we carry out an order of 18 magnitude analysis by comparing an effective diffusion time scale with the cooling time scale.

19 This method, which we will briefly review below, has been successfully used to elucidate closure 20 temperatures for cooling mono-mineralic systems (e.g., Dodson, 1976; Albarède, 1995).

\section{2.1. Closure temperature for cooling mono-mineralic systems}


The time scale of diffusive re-equilibration is a useful concept. To within a constant factor,

2 Dodson's equation can be obtained by comparing an accumulated mean square diffusive

3 penetration distance with the square of an effective grain radius (e.g., Taylor et al., 1975; Lasaga,

4 1998; Cherniak and Watson, 2007; Zhang, 2008; Watson and Cherniak, 2013) or by comparing a

5 diffusion time scale with a cooling time scale (e.g., Dodson, 1976; Albarède, 1995). If $D_{A}$ is the

6 temperature-dependent diffusion coefficient for an element in mineral A, the characteristic

7 diffusion time is given by the usual expression

$$
t_{D}=\frac{3 \beta d_{A}^{2}}{D_{A}},
$$

9 where $\beta$ is a constant, depending on mineral shape and boundary condition. It takes on values of

101,4 , or 5 for diffusion in plane sheet of half-length $d_{A}$, cylinder or sphere of radius $d_{A}$, 11 respectively (Liang, 2014). For mineral aggregates, the $\beta$ may take on a range of values (1 5),

12 depending on mineral shape and grain size distribution. The cooling time scale or constant $(\tau)$, 13 according to Dodson (1973), is defined as the time it takes to decrease $D_{A}$ by a factor of $e$ or $1463 \%$, viz.,

$$
\tau=-\frac{d \ln D_{A}}{d t}=\frac{R T_{c}^{2}}{E_{A} \dot{s}},
$$
where $t$ is time. The mineral is effectively closed to diffusive exchange with its surrounding

17 when the cooling time is shorter than the diffusion time. At closure temperature $T_{c}$, Eqs. 3 and 4 18 differ by a constant factor A', viz.

$$
\frac{3 \beta d_{A}^{2}}{D_{A}^{c}}=A^{\prime} \frac{R T_{c}^{2}}{E_{A} \dot{s}},
$$

20 where $D_{A}^{c}$ is diffusion coefficient at the closure temperature $T_{c}$. Eq. 5 is the same as Dodson's 21 equation for closure temperature (Eq. 1b) when the geometry function $G=\ln \left(A^{\prime} / 3 \beta\right)$. 


\section{2.2. Closure temperature for cooling bi-mineralic systems}

3 The approach outlined above can also be used to obtain an equation for closure temperature

4 for cooling bi-mineralic systems. According to the analysis of Liang (2014), the diffusive re-

5 equilibration time for a trace element in a bi-mineralic aggregate is a weighted sum of

6 characteristic diffusion times for the trace element in the two minerals and takes on the simple

7 expression

$$
t_{D}=\frac{\phi_{B}}{\beta\left(\phi_{A} k_{A B}+\phi_{B}\right)} \frac{d_{A}^{2}}{D_{A}}+\frac{\phi_{A} k_{A B}}{\beta\left(\phi_{A} k_{A B}+\phi_{B}\right)} \frac{d_{B}^{2}}{D_{B}},
$$

9 where $\beta$ is a constant depending on geometry of the mineral grain; and $\phi$ again is the volume

10 fraction of mineral A or mineral B. The bulk or effective diffusive exchange rate between 11 mineral A and mineral B in the REV, $\alpha$, is inversely proportional to $t_{D}$, viz.,

$$
\alpha=\frac{3 \beta\left(\phi_{A} k_{A B}+\phi_{B}\right)}{\phi_{B} \frac{d_{A}^{2}}{D_{A}}+\phi_{A} k_{A B} \frac{d_{B}^{2}}{D_{B}}} .
$$

13 Eqs. 6 and 7 were obtained from approximate solutions to the diffusion equations governing

14 diffusive exchange between minerals $\mathrm{A}$ and $\mathrm{B}$ in the bi-mineralic aggregate with effective 15 diffusion radii of $d_{A}$ and $d_{B}$ using the method of parabolic approximation (for details see Liang, 16 2014). Similar to Dodson (1973), we introduce a cooling time constant $\tau$, defined as the time it

17 takes to reduce the effective diffusive exchange rate $\alpha$ by a factor of $e$, viz.

$$
\alpha=\alpha_{0} \exp \left(-\frac{t}{\tau}\right)
$$

which can also be written as 


$$
\frac{1}{\tau}=-\frac{d \ln \alpha}{d t}
$$

2 Upon differentiation of Eq. 7, we obtain the cooling time constant for the bi-mineralic system,

$$
\tau=-\frac{\left(\phi_{A} k_{A B}+\phi_{B}\right)\left(\phi_{B} \frac{d_{A}^{2}}{D_{A}}+\phi_{A} k_{A B} \frac{d_{B}^{2}}{D_{B}}\right) R T^{2}}{\phi_{B} \phi_{A} k_{A B} E_{k}\left(\frac{d_{A}^{2}}{D_{A}}-\frac{d_{B}^{2}}{D_{B}}\right)+\left(\phi_{A} k_{A B}+\phi_{B}\right)\left(\phi_{B} E_{A} \frac{d_{A}^{2}}{D_{A}}+\phi_{A} k_{A B} E_{B} \frac{d_{B}^{2}}{D_{B}}\right)} \frac{d t}{d T} .
$$

4 The cooling bi-mineralic system is effectively closed to diffusive mass transfer when the

5 characteristic cooling time is considerably smaller than the diffusive exchange time, i.e., $\tau<t_{D}$.

6 To be consistent with Dodson's formulation, we set

$$
\frac{\exp (G)}{\beta} \tau=t_{D}
$$

8 where $G$ again is the geometry function as in Dodson's equation (Eq. 1). From Eqs. 6 and 9, we

9 have an algebraic equation for closure temperature for a cooling bi-mineralic system

$$
\frac{\phi_{B} E_{A} \frac{d_{A}^{2} \dot{s}}{D_{A}^{c}}+\phi_{A} k_{A B}^{c} E_{B} \frac{d_{B}^{2} \dot{s}}{D_{B}^{c}}}{\left(\phi_{A} k_{A B}^{c}+\phi_{B}\right) R T_{c}^{2}}+\frac{\phi_{B} \phi_{A} k_{A B}^{c} E_{k}}{\left(\phi_{A} k_{A B}^{c}+\phi_{B}\right)^{2} R T_{c}^{2}}\left(\frac{d_{A}^{2} \dot{s}}{D_{A}^{c}}-\frac{d_{B}^{2} \dot{s}}{D_{B}^{c}}\right)=\exp (G),
$$

11 where the cooling rate $\dot{s}$, diffusion coefficients $\left(D_{A}^{c}\right.$ and $\left.D_{B}^{c}\right)$ and partition coefficient $\left(k_{A B}^{c}\right)$ are

12 all evaluated at the closure temperature $T_{c}$.

\section{DISCUSSION}

15 Eq. 10 encapsulates all the relevant parameters for closure temperature for cooling bi-

16 mineralic systems: cooling rate, diffusion coefficients, mineral-mineral partition coefficient,

17 activation energies for diffusion, exchange energy for trace element partitioning, effective grain

18 sizes, and modal abundances. The first three parameters are evaluated at the closure temperature 
$1 T_{c}$ and hence may be taken as extrinsic, whereas the last three parameters are intrinsic to the bi-

2 mineralic system. The first term on the left hand side of Eq. 10 accounts for the temperature- or

3 time-dependent diffusion coefficients, whereas the second term on the left hand side of Eq. 10

4 arises from the temperature-dependent partition coefficient, as $d \ln k_{A B} / d t=E_{k} / R T^{2}$. The

5 activation energies for cation diffusion in silicate minerals are typically larger than the exchange

6 energy for mineral-mineral partitioning. For example, the exchange energies for REE

7 partitioning between orthopyroxene and clinopyroxene $(83 \sim 38 \mathrm{~kJ} / \mathrm{mol}$, from La to $\mathrm{Yb}$, according

8 to the model of Liang et al., 2013) are 3 10 times smaller than the activation energies for REE

9 diffusion in diopside (530 400 kJ/mol, from $\mathrm{La}$ to $\mathrm{Yb}$ in cpx, Van Orman et al., 2001) and Mg-

10 rich orthopyroxene $(369 \mathrm{~kJ} / \mathrm{mol}$ for REE, Cherniak and Liang, 2007; 218-262 kJ/mol for Nd,

11 Sano et al., 2011). This situation is also true for a number of trace elements in the pyroxenes

12 (e.g., Ti, $\mathrm{Hf}, \mathrm{U}, \mathrm{Th}, \mathrm{Sr}, \mathrm{Pb}, \mathrm{Sc}, \mathrm{Cr}$, and $\mathrm{Mn}$ ) according to the published diffusion and partitioning

13 data (Sneeringer et al., 1984; Seitz et al., 1999; Van Orman et al., 1998; Witt-Eickschen and

14 O'Neill, 2005; Dimanov and Wiedenbeck, 2006; Ganguly et al., 2007; Cherniak and Liang,

15 2012; Block and Ganguly, 2014). Hence the second term in Eq. 10 is negligible in many

16 practical applications. The second term also vanishes when the differences in diffusion time

17 between mineral A and mineral B at the closure temperature is very small, i.e., $d_{A}^{2} / D_{A}^{c} \simeq d_{B}^{2} / D_{B}^{c}$.

18 An important property of Eq. 10 is that it reduces to Dodson's equation (Eq. 1b) when one of

19 the minerals serves as "an effective infinite" reservoir to the other mineral. This can be achieved

20 under two limiting conditions or through their combination. Let $w_{A}^{e-c}$ and $w_{B}^{e-c}$ be the equilibrium

21 mass fractions of the element of interest in minerals $\mathrm{A}$ and $\mathrm{B}$ relative to their total mass in the

$22 \mathrm{REV}$ at the closure temperature $T_{c}$, 


$$
w_{A}^{e-c}=\frac{\phi_{A} \bar{C}_{A}^{e-c}}{\phi_{A} \bar{C}_{A}^{e-c}+\phi_{B} \bar{C}_{B}^{e-c}}=\frac{\phi_{A} k_{A B}^{c}}{\phi_{A} k_{A B}^{c}+\phi_{B}}
$$

$$
w_{B}^{e-c}=\frac{\phi_{B} \bar{C}_{B}^{e-c}}{\phi_{A} \bar{C}_{A}^{e-c}+\phi_{B} \bar{C}_{B}^{e-c}}=\frac{\phi_{B}}{\phi_{A} k_{A B}^{c}+\phi_{B}},
$$

3 where $\bar{C}_{A}^{e-c}$ and $\bar{C}_{B}^{e-c}$ are the equilibrium concentrations for the trace element in minerals $\mathrm{A}$ and

$4 \quad \mathrm{~B}$ in the REV at $T_{c}$, respectively. The equilibrium concentrations are related to each other

5 through the mineral-mineral partition coefficient, i.e., $k_{A B}^{e-c}=\bar{C}_{A}^{e-c} / \bar{C}_{B}^{e-c}$. Eq. 10 then takes on a 6 simpler form,

$$
w_{B}^{e-c} \frac{E_{A} \dot{s}}{R T_{c}^{2}} \frac{d_{A}^{2}}{D_{A}^{c}}+w_{A}^{e-c} \frac{E_{B} \dot{s}}{R T_{c}^{2}} \frac{d_{B}^{2}}{D_{B}^{c}}+w_{A}^{e-c} w_{B}^{e-c} \frac{E_{k} \dot{s}}{R T_{c}^{2}}\left(\frac{d_{A}^{2}}{D_{A}^{c}}-\frac{d_{B}^{2}}{D_{B}^{c}}\right)=\exp (G) .
$$

8 Eq. 12 recovers Dodson's equation for mineral A (Eq. 1b) when $w_{A}^{e-c} \rightarrow 0$. That is when the

9 volume fraction of mineral A is much smaller than mineral $\mathrm{B}\left(\phi_{A} \ll \phi_{B}\right)$ and/or when the mineral

10 A-B partition coefficient at the closure temperature is much smaller than one (i.e., $k_{A B}^{c} \ll 1$ ).

11 Similarly, Eq. 12 reduces to Dodson's equation for mineral B when $w_{B}^{e-c} \rightarrow 0$. In this latter case,

12 mineral A effectively serves as an infinite sink for diffusant of interest initially in mineral B, as

13 the equilibrium concentration in mineral $\mathrm{A}$ is much larger than that in mineral B (i.e., $k_{A B}^{c} \gg 1$ ).

14 This buffering effect is referred to as "minor's rule" in Liang (2014) for diffusive re-equilibration

15 in bi-mineralic systems, viz., the mineral that contains lesser amount of the trace element of

16 interest in the bi-mineralic system contributes more to the overall diffusive re-equilibration time.

17 As a corollary of minor's rule, we can make the following general statement: closure

18 temperatures for cooling bi-mineralic systems are bounded by the closure temperatures for the

19 trace element in the two mono-mineralic systems consisting of mineral $\mathrm{A}$ and mineral B, 20 respectively. 
Minor's rule is particularly useful in situations when abundance of the element of interest is

2 much smaller in one mineral relative to the other. Some examples for crustal rocks include the

3 Ti-in-quartz, Ti-in-zircon, and Zr-in-rutile thermometers of Watson and coworkers that are based

4 on the temperature dependent $\mathrm{Ti}$ solubility in quartz or zircon coexisting with rutile (or $\mathrm{Zr}$

5 solubility in rutile coexisting with zircon) (Watson and Harrison, 2005; Wark and Watson, 2006;

6 Watson et al., 2006; Thomas et al., 2010). Similar examples for mafic rocks include the Mg-in-

7 plagioclase thermometer of Faak et al. (2013) and the Al-in-olivine thermometer of Coogan et al.

8 (2014). The former is based on the temperature sensitive Mg partitioning between plagioclase

9 and clinopyroxene, while the latter is based on the temperature dependent Al partitioning

10 between olivine and spinel. Here $\mathrm{Mg}$ is a minor element in plagioclase but a major element in

11 clinopyroxene; $\mathrm{Al}$ is a trace element in olivine but a major element in spinel. According to

12 minor's rule, temperatures derived from the Ti-in-quartz thermometer, the Mg-in-plagioclase

13 thermometer, and the Al-in-olivine thermometer should correspond to the closure temperatures

14 of Ti diffusion in quartz, $\mathrm{Mg}$ diffusion in plagioclase, and $\mathrm{Al}$ diffusion in olivine, respectively,

15 independent of Ti diffusion in rutile (Cherniak et al., 2007), Mg diffusion in clinopyroxene (Faak

16 et al., 2014), and Al diffusion in spinel.

17 The characteristic diffusion time $t_{D}$ in Eq. 6 (hence the effective diffusive exchange rate $\alpha$ in

18 Eq. 7) was obtained by approximating diffusion profiles in minerals A and B at a given time as

19 functions of second order polynomials (Liang, 2014). Since the parabolic approximation is

20 applicable only when diffusion has already penetrated into the mineral cores (e.g., Goodman,

21 1964; Hill, 1987; Bodinier et al., 1990; Liang, 2003), Eqs. 10 and 12 are valid under conditions

22 similar to that of Dodson's (Eqs. 1a and 1b) and hence may be taken as a generalization of

23 Dodson's equation to cooling bi-mineralic systems. However, these equations are not applicable 
1 to situations where diffusion has not affected mineral core concentrations, as discussed in the

2 model of Ganguly and Tirone (1999).

3 Another simplification in the derivation of the diffusion time $t_{D}$ in Eq. 6 is the use of effective

4 diffusion radii $d_{A}$ and $d_{B}$, which is a standard practice in diffusion modeling of poly-mineralic

5 systems. In real rocks, mineral grain size and surface area vary within REV and grain size

6 distribution may also play an important role in determining closure temperatures: consider a rock

7 with bi-modal grain size distribution or log-normal grain size distribution. Such more

8 complicated but real cases can be treated numerically. Nonetheless, the key factors controlling

9 closure temperatures for cooling bi-mineralic systems identified through the simple analysis

10 present in this study likely remain valid.

\section{4. CLOSURE TEMPERATURES OF REE IN PYROXENES}

13 To further illustrate the key features of Eq. 10, we consider closure temperatures of REE in

14 an effective bi-mineralic system that consists of orthopyroxene (opx) and clinopyroxene (cpx).

15 These two pyroxenes are frequently observed in ultramafic and mafic rocks. Figure 1a displays

16 REE diffusion coefficients in cpx and opx as a function of temperature. Van Orman et al. (2001)

17 demonstrated that diffusion rates of REE in diopside depend strongly on their ionic radii (green

18 to yellow lines in Fig. 1a), whereas Cherniak and Liang (2007) showed that diffusion rates of

19 REE in enstatite are not sensitive to their ionic radii (red dashed line). Orthopyroxene-

20 clinopyroxene REE partition coefficients depend primarily on temperature, ionic radius, and

21 pyroxene compositions (e.g., Stosch, 1982; Witt-Eickschen and O’Neill, 2005; Lee et al., 2007;

22 Liang et al. 2013). Figure 1b displays opx-cpx REE partition coefficients for three choices of 23 temperature using the model of Liang et al. (2013) which was derived from pyroxene-basalt REE 
1 partitioning models (Sun and Liang, 2012; Yao et al., 2012) and validated by well-equilibrated

2 spinel lherzolite xenoliths. Relative to cpx, light REE are considerably more incompatible in opx $3\left(k_{A B} \sim 0.002-0.04\right.$, where $\left.\mathrm{A}=\mathrm{opx}, \mathrm{B}=\mathrm{cpx}\right)$ than heavy REE in opx $\left(k_{A B} \sim 0.1-0.4\right)$. During

4 subsolidus re-equilibration, REE are strongly and preferentially partitioned into cpx relative to 5 opx. Hence, according to minor's rule, cpx may serve as a sink for REE redistribution in opx 6 when cpx modal abundance in the opx-cpx aggregate is not too small.

7 Figures 2a-2c display closure temperatures for REE in cpx + opx aggregates as a function of 8 effective diffusion radius for a cooling rate of $10^{\circ} \mathrm{C} / \mathrm{Myr}$ and for three choices of opx:cpx volume 9 proportions using REE diffusion data of Van Orman et al. (2001) for cpx and Cherniak and 10 Liang (2007) for opx. In each case, closure temperatures for $\mathrm{Ce}$ and $\mathrm{Yb}$ in mono-mineralic cpx 11 and REE in mono-mineralic opx, calculated using Dodson's equation (Eq. 1a), are also shown

12 for reference. For purpose of illustration, we first consider cases with equal grain size $\left(d_{o p x}=\right.$ $\left.13 d_{c p x}\right)$. For two-pyroxene aggregates with more than $20 \% \mathrm{cpx}$, the closure temperature is 14 determined primarily by that of opx, because of the lower abundances of REE in opx in the REV 15 (or very small REE opx-cpx partition coefficients) (cf. Fig. 1b and Eq. 12). Clinopyroxene in this 16 case serves effectively as a large reservoir for REE redistribution in opx (Fig. 2a). The buffering 17 role of cpx has been demonstrated in the numerical simulations of Cherniak and Liang (2007) 18 who examined diffusive re-distribution of REE between opx and cpx (in 1:1 volume proportion) 19 under a prescribed cooling rate. They showed that large differences in diffusive and partitioning 20 behaviors of REE between opx and cpx result in very large relative core-to-rim compositional 21 variations in opx, but very small relative compositional variations in cpx (see their Fig. 11).

22 However, when cpx modal abundance decreases, the equilibrium mass fractions of REE in $23 \mathrm{cpx}, w_{c p x}^{e-c}$, also decreases. According to Eq. 12, clinopyroxene eventually becomes the minor 
1 component for REE in the orthopyroxenite (or harzburgite). Figures $2 b$ and $2 c$ show that $c p x$

2 becomes important when its volume fraction is less than 5\%. Both lherzolite and harzburgite

3 contain significant amount of olivine. Clinopyroxene is important in determining closure

4 temperatures for REE between opx and cpx in these natural rocks only when its modal

5 abundance is less than 1 2\% (e.g., in a depleted harzburgite).

6 In many peridotite samples, the average grain size of $\mathrm{cpx}$ is smaller than that of opx. At

7 constant volume proportion, the effect of a smaller cpx grain size is to further reduce the role of

8 cpx in controlling the closure temperature for the two-pyroxene system, as the characteristic

9 diffusion time for cpx scales with its grain size to the squares, i.e., $d_{c p x}^{2} / D_{c p x}^{c}$ in Eq. 12. Figures

$103 \mathrm{a}$ and $3 \mathrm{~b}$ show that the smaller cpx grain size effect is especially stronger for the light to middle

11 REE.

12 Sano et al. (2011) examined Nd diffusion in Mg-rich opx along three crystallographic

13 directions and noted some anisotropy. Although their measured diffusivities agree fairly well

14 with data reported in Cherniak and Liang (2007, normal to (210)) at temperatures above $1050^{\circ} \mathrm{C}$,

15 their measurements at $975^{\circ} \mathrm{C}$ and $1025^{\circ} \mathrm{C}$ appear higher than trend established by the latter data

16 (see supplementary Figure S1 for a detailed comparison of the two studies). Consequently,

17 activation energies for $\mathrm{Nd}$ diffusion in opx reported in Sano et al. (216 269 kJ/mol) are

18 considerably smaller than values presented in Cherniak and Liang (321 384 kJ/mol) (for a

19 graphic comparison see Supplementary Figure S2). [Interestingly, nine out of 10 measured

20 diffusivities along b direction in Sano et al. (2011) agree very well with data reported in

21 Cherniak and Liang (2007, normal to (210), see supplementary Figure S1.] Figures 4a-4c are

22 similar to Figs. 2a-2c except the Arrhenius relation of Sano et al. (2011) for Nd diffusion along c

23 direction in opx was used to calculate the closure temperatures. A larger diffusivity and smaller 
1 activation energy for REE diffusion in opx (hence the smaller ratio $E_{A} / D_{A}^{c}$ in Eq. 12) expand the

2 role of cpx (mineral B in Eq. 12) and lower the closure temperatures for the cpx + opx bi-

3 mineralic aggregates (cf. Figs. 2 and 4). More study is needed to further resolve REE diffusion in

4 opx at low temperatures.

5 In a recent study, Liang et al. (2013) developed a REE-in-two-pyroxene thermometer (with

6 temperature designated as $T_{\mathrm{REE}}$ ) that is based on temperature sensitive REE partitioning between

7 coexisting opx and cpx. Through both numerical simulations (Yao and Liang, in press) and

8 theoretical analysis (Liang, 2014), they showed that for cooling opx-cpx systems, $T_{\text {REE }}$ is

9 equivalent to the average closure temperature of REE in two-pyroxene dominant rocks. As

10 applications of this new thermometer, $T_{R E E}$ for abyssal peridotites (Liang et al., 2013), peridotites

11 from mantle sections of ophiolites around the world (Dygert and Liang, 2015), and selected

12 peridotite xenoliths from the North China Craton (Wang et al., 2015) were calculated. Results

13 from these studies showed that $T_{R E E}$ for the peridotites are $50-300^{\circ} \mathrm{C}$ higher than temperatures

14 derived from the major element based two-pyroxene thermometer of Brey and Köhler (1990,

$\left.15 T_{B K N}\right)$ for the same samples (Fig. 5). This difference in temperature $\left(\triangle \mathrm{T}=T_{R E E}-T_{B K N}\right)$ can be

16 understood in terms of differences in closure temperature between the trivalent REE and divalent

$17 \mathrm{Fe}-\mathrm{Mg}($ and $\mathrm{Ca}$ ) in the pyroxenes. The large range in temperature difference may be attributed in

18 part to variations in cpx modal abundance and grain size in the peridotites, and possibly REE

19 diffusivities in opx, as demonstrated in Figs. 2-4. With a better understanding of closure

20 temperatures in cooling bi-mineralic systems, it is possible to develop a quantitative model that

21 can be used to infer cooling rates of mafic and ultramafic rocks based on temperatures and

22 temperature differences derived from major element and REE based two-pyroxene thermometers

23 (Dygert and Liang, 2015; Wang et al., 2015; Yao et al., in press). 


\section{SUMMARY}

3 A simple model for closure temperature of a trace element in cooling bi-mineralic aggregates

4 is obtained by comparing the characteristic diffusion time and an effective cooling time for the

5 bi-mineralic systems. These time scales were obtained by solving grain-scale diffusion equations

6 using the polynomial approximation that is valid when diffusion has already penetrated into the

7 cores of the crystals. The model presented in this study is physically intuitive and helps to

8 elucidate key parameters affecting closure temperature for a trace element in cooling bi-

9 mineralic systems. In general, the mineral that has higher activation energy for diffusion, larger

10 diffusion time $\left(d^{2} / D\right)$ and smaller equilibrium mass fraction of the trace element in the system

$11\left(w^{c-e}\right)$ contributes more to the closure temperature for the cooling bi-mineralic system (Eq. 12).

12 The effects of mineral proportion and mineral-mineral trace element partition coefficient are

13 encapsulated in a single parameter, the equilibrium mass fraction of the trace element in the

14 system. The latter helps to explain the buffering effect of the second mineral during diffusive

15 exchange and the minor's rule. The closure temperatures for a trace element in cooling bi-

16 mineralic systems are bounded by the closure temperatures for the trace element in the two

17 mono-mineralic systems.

18 Application to closure temperatures of REE in opx and cpx bi-mineralic systems highlights

19 the importance of the minor's rule. Closure temperatures for REE in two-pyroxene bearing rocks

20 are controlled primarily by REE diffusion in opx unless the modal abundance of cpx is very

21 small or/and the effective grain size of cpx is considerably larger than that of opx. The latter has

22 important implications for the interpretation of temperatures derived from the REE-in-two-

23 pyroxene thermometer. 
3 Acknowledgments. I would like to thank Nick Dygert, Jiba Ganguly and Lijing Yao for useful

4 discussion and suggestions. The paper benefited from thoughtful review comments from Bruce

5 Watson, Ralf Dohmen and the editor Marc Norman. This work was supported in part by NSF

6 grant EAR-1220076 and NASA grant NNX13AH07G. 


\section{REFERENCES}

Albarède F. (1995) Introduction to Geochemical Modeling. Cambridge University Press. Cambridge.

Bloch E. and Ganguly J. (2014) 176Lu-176Hf and 147Sm-143Nd ages of the Martian shergottites: Evaluation of the shock-resetting hypothesis through diffusion kinetic experiments and modeling, and petrological observations. Earth Planet. Sci. Lett. 395, 173183.

Bodinier J. L., Vasseur G., Vernieres J., Dupuy C., and Fabries J. (1990) Mechanisms of mantle metasomatism: Geochemical evidence from the Lherz orogenic peridotite. J. Petrol. 31, 597628.

Brey G. and Köhler T. (1990) Geothermobarometry in four-phase lherzolites II. New thermobarometers, and practical assessment of existing thermobarometers. J. Petrol. 31, 1353.

Cherniak D. and Liang Y. (2007) Rare earth element diffusion in natural enstatite. Geochim. Cosmochim. Acta 71, 1324-1340.

Cherniak D. and Liang Y. (2012) Ti diffusion in natural pyroxene. Geochim. Cosmochim. Acta $98,31-47$.

Cherniak D. and Watson E. B. (2007) Ti diffusion in zircon. Chem. Geol. 242, 470-483.

Cherniak D., Watson E. B., and Wark D. A. (2007) Ti diffusion in quartz. Chem. Geol. 236, 6574.

Coogan L. A., Saunders A. D., and Wilson R. N. (2014) Aluminum-in-olivine thermometry of primitive basalts: Evidence of an anomalously hot mantle source for large igneous provinces. Chem. Geol. 368, 1-10.

Crank J. (1975) The Mathematics of Diffusion. Clarendon Press, Oxford.

Dimanov A. and Wiedenbeck M. (2006) (Fe, Mn)-Mg interdiffusion in natural diopside: effect of pO2. Eur. J. Mineral. 18, 705-718.

Dodson M. H. (1973) Closure temperature in cooling geochronological and petrological systems. Contrib. Mineral. Petrol. 40, 259-274.

Dodson M. H. (1976) Kinetic processes and thermal history of slowly cooling solids. Nature 259, 551-553.

Dodson M. H. (1986) Closure profiles in cooling systems. Mat. Sci. Forum 7, 145-154.

Dygert N. and Liang Y. (2015) Contrasting cooling rates as recorded by REE in coexisting pyroxenes in ophiolitic and abyssal peridotites. Earth Planet. Sci. Lett. doi: 10.1016/j.eps1.2015.02.042.

Ehlers K. and Powell R. (1994) An empirical modification of Dodson's equation for closure temperature in binary systems. Geochim. Cosmochim. Acta 58, 241-248.

Eiler J. M., Baumgartner L. P., and Valley J. W. (1992) Intercrystalline stable isotope diffusion: a fast grain boundary model. Contrib. Mineral. Petrol. 112, 543-557.

Faak K., Chakraborty S., and Coogan L. A. (2013) Mg in plagioclase: Experimental calibration of a new geothermometer and diffusion coefficients. Geochim. Cosmochim. Acta 123, 195217. 
Faak K., Coogan L. A., Chakraborty S. (2013) A new Mg-in-plagioclase geospeedometer for the determination of cooling rates of mafic rocks. Geochim. Cosmochim. Acta 140, 691-707.

Ganguly J. and Tirone M. (1999) Diffusion closure temperature and age of a mineral with arbitrary extent of diffusion theoretical formulation and applications. Earth Planet. Sci. Lett. 170, 131-140.

Ganguly J., Ito M., and Zhang X. (2007) Cr diffusion in orthopyroxene: Experimental determination, ${ }^{53} \mathrm{Mn}-{ }^{53} \mathrm{Cr}$ thermochronology, and planetary applications. Geochim. Cosmochim. Acta 71, 3915-3925.

Gardés E. and Montel J-M. (2009) Opening and resetting temperatures in heating geochronological systems. Contrib. Mineral. Petrol. 158, 185-195.

Giletti B. J. (1986) Diffusion effects on oxygen isotope temperatures of slowly cooled igneous and metamorphic rocks. Earth Planet. Sci. Lett. 77, 218-228.

Goodman T. R. (1964) Application of integral methods to transient nonlinear heat transfer. In: Advances in Heat Transfer (ed. T. F. Irvine Jr. and J. P Hartnett), Vol. 1, pp51-122.

Jenkin G. R. T., Farrow C. M., Fallick A. E., and Higgins D. (1994) Oxygen isotope exchange and closure temperatures in cooling rocks. J. metamorphic Geol. 12, 221-235.

Jenkin G. R. T., Gogers G., Fallick A.E., and Farrow C. M. (1995) Rb-Sr closure temperatures in bi-mineralic rocks: a mode effect and test for different diffusion models. Chem. Geol. 122, 227-240.

Hill J. M. (1987) One-dimensional Stefan Problem: An Introduction. Longman, New York.

Lasaga A. C. (1983) Geospeedometry: An extension of geothermometry. In: Kinetics and Equilibrium in Mineral Reactions (edited by S. K. Saxena). Advances in Physical Geochemistry 3, 81-114.

Lasaga A. C. (1998) Kinetic Theory in the Earth Sciences. Princeton University Press, Princeton.

Lasaga A. C., Richardson S. M., and Holland H. D. (1977) The mathematics of cation diffusion and exchange between silicate minerals during retrograde metamorphism. In: Energetics of Geological Processes (edited by S. K. Saxena and S. Bhattacharji), Springer-Verlag, New York, pp353-388.

Lee C. T. A., Harbert A. and Leeman W. P. (2007) Extension of lattice strain theory to mineral/mineral rare-earth element partitioning: An approach for assessing disequilibrium and developing internally consistent partition coefficients between olivine, orthopyroxene, clinopyroxene and basaltic melt. Geochim. Cosmochim. Acta 71, 481-496.

Liang Y. (2003) Kinetics of crystal-melt reaction in partially molten silicates: 1. Grain scale processes. Geochem. Geophys. Geosyst. 4, 1045, doi:10.1029/2002GC000375.

Liang Y. (2014) Time scales of diffusive re-equilibration in bi-mineralic systems with and without a fluid phase. Geochim. Cosmochim. Acta 132, 274-287.

Liang Y., Sun C., and Yao L. (2013) A REE-in-two-pyroxene thermometer for mafic and ultramafic rocks. Geochim. Cosmochim. Acta 102, 246-260.

Onorato P. I. K., Hopper R. W., Yinnon H., Uhlmann D. R., Taylor L. A., Garrison J. R., and Hunter R. (1981) Solute partitioning under continuous cooling conditions as a cooling rate indicator. J. Geophys. Res. 86, 9511-9518. 
Powell R. and White L. (1995) Diffusive equilibration between minerals during cooling: an analytical extension to Dodson's equation for closure in one dimension. Geol. J. 30, 297-305.

Sano J., Ganguly J., Hervig R., Dohmen R., and Zhang X. (2011) Neodymium diffusion in orthopyroxene: Experimental studies and applications to geological and planetary problems. Geochim. Cosmochim. Acta 75, 4684-4698.

Seitz H-M., Altherr R., and Ludwig T. (1999) Partitioning of transition elements between orthopyroxene and clinopyroxene in peridotitic and websteritic xenoliths: New empirical geothermometers. Geochim. Cosmochim. Acta 63, 3967-3982.

Sneeringer M., Hart S. R., and Shimizu N. (1984) Strontium and samarium diffusion in diopside. Geochim. Cosmochim. Acta 48, 1589-1608.

Spear F. S. (1991) On the interpretation of peak metamorphic temperatures in light of garnet diffusion during cooling. J. metamorphic Geol. 9, 379-388.

Stosch H. G. (1982) Rare earth element partitioning between minerals from anhydrous spinel peridotite xenoliths. Geochim. Cosmochim. Acta 46, 793-811.

Sun C. and Liang Y. (2012) Distribution of REE between clinopyroxene and basaltic melt along a mantle adiabat: Effects of major element composition, water, and temperature. Contrib. Mineral. Petrol. 163, 807-823.

Taylor L. A., Uhlmann D. R., Hopper R. W., and Misra K. C. (1975) Absolute cooling rates of lunar rocks: Theory and application. Proc. Lunar Sci. Conf. $6^{\text {th }}, 181-191$.

Thomas J. B., Watson E. B., Spear F. S., Shemella P. T., Nayak S., and Lanzirotti A. (2010) TitaniQ under pressure: the effect of pressure and temperature on the solubility of $\mathrm{Ti}$ in quartz. Contrib. Mineral. Petrol. 160, 743-759.

Van Orman J. A., Grove, T. L., and Shimizu N. (1998) Uranium and thorium diffusion in diopside. Earth Planet. Sci. Lett. 160, 505-519.

Van Orman J. A., Grove, T. L. and Shimizu N. (2001) Rare earth element diffusion in diopside: Influence of temperature, pressure, and ionic radius, and an elastic model for diffusion in silicates. Contrib. Mineral. Petrol. 141, 687-703.

Wang C., Liang Y., and Xu W. (2015) On the significance of temperatures derived from major element and REE based two-pyroxene thermometers for mantle xenoliths from the North China Craton. Lithos http://dx.doi.org/10.1016/j.lithos.2015.01.022.

Wark D. A. and Watson E. B. (2006) TitaniQ: a titanium-in-quartz geothermometer. Contrib. Mineral. Petrol. 152, 743-754.

Watson E. B. and Harrison T. M. (2005) Zircon thermometer reveals minimum melting conditions on earliest Earth. Science 308, 841-844.

Watson E. B. and Cherniak D. J. (2013) Simple equations for diffusion in response to heating. Chem. Geol. 335, 93-104.

Watson E. B., Wark D. A., and Thomas J. B. (2006) Crystallization thermometers for zircon and rutile. Contrib. Mineral. Petrol. 151, 413-433.

Witt-Eickschen G. and O'Neill H. S. C. (2005) The effect of temperature on the equilibrium distribution of trace elements between clinopyroxene, orthopyroxene, olivine and spinel in upper mantle peridotite. Chem. Geol.221, 65-101. 
1 Yao L., Sun C. and Liang Y. (2012) A parameterized model for REE partitioning between low2 Ca pyroxene and basaltic melts with applications to adiabatic mantle melting and pyroxenite3 derived melt and peridotite interaction. Contrib. Mineral. Petrol. 164, 261-280.

4 Yao L. and Liang Y. (2015) Closure temperature in cooling bi-mineralic systems: I. Definition 5 and with application to REE-in-two-pyroxene thermometer. Geochim. Cosmochim. Acta, in 6 press.

7 Zhang Y. (2008) Geochemical Kinetics. Princeton University Press, Princeton. 


\section{Figure Captions}

3 Figure 1. REE diffusion coefficients and partition coefficients used in model calculations. (a) Arrhenius plot showing variations of REE diffusion coefficients in diopside and enstatite (Van Orman et al., 2001; Cherniak and Liang, 2007). (b) Partition coefficients of REE between orthopyroxene (opx) and clinopyroxene (cpx) at three selected temperatures (Liang et al., 2013). Modified after Liang (2014).

Figure 2. Variations of closure temperatures for REE in two-pyroxene aggregates as a function of effective diffusion radius at a cooling rate of $10^{\circ} \mathrm{C} / \mathrm{Myr}$ and for three choices of orthopyroxene-clinopyroxene volume proportions. (a) $\phi_{o p x}: \phi_{c p x}=50: 50$; $\phi_{o p x}: \phi_{c p x}=80: 20$; and (c) $\phi_{o p x}: \phi_{c p x}=95: 5$. For simplicity, effective grain sizes of the two pyroxenes are set the same. Closure temperatures of $\mathrm{Ce}$ and $\mathrm{Yb}$ in clinopyroxene (dashed blue lines) and REE in orthopyroxene (heavy black line) are also shown. REE diffusion data are from Van Orman et al. (2001) for clinopyroxene and Cherniak and Liang (2007) for orthopyroxene. See text for further discussion.

Figure 3. Variations of closure temperatures for REE in two-pyroxene aggregates as a function of effective diffusion radius of orthopyroxene at a cooling rate of $10^{\circ} \mathrm{C} / \mathrm{Myr}$ and for two choices of clinopyroxene grain sizes. (a) $d_{c p x}=d_{o p x} / 2$; and (b) $d_{c p x}=d_{o p x} / 4$. The orthopyroxene-clinopyroxene volume proportion is fixed at 95:5. Symbols are the same as those used in Fig. 2. 
1 Figure 4. Variations of closure temperatures for REE in two-pyroxene aggregates as a function of effective diffusion radius at a cooling rate of $10^{\circ} \mathrm{C} / \mathrm{Myr}$ and for three choices of orthopyroxene-clinopyroxene volume proportions. (a) $\phi_{o p x}: \phi_{c p x}=50: 50$; $\phi_{o p x}: \phi_{c p x}=80: 20$; and (c) $\phi_{o p x}: \phi_{c p x}=95: 5$. For simplicity, effective grain sizes of the two pyroxenes are set the same. Closure temperatures of $\mathrm{Ce}$ and $\mathrm{Yb}$ in clinopyroxene (dashed blue lines) and REE in orthopyroxene (heavy black line) are also shown. REE diffusion data are from Van Orman et al. (2001) for clinopyroxene and Sano et al. (2011) for orthopyroxene.

Figure 5. Comparison between temperatures derived from the REE-in-two-pyroxene thermometer $\left(T_{R E E}\right)$ and those calculated using the major element based two-pyroxene thermometer of Brey and Köhler (1990, $T_{B K N}$, assuming a pressure of $1 \mathrm{GPa}$ ) for abyssal and ophiolitic peridotites. For clarity, temperature ranges for abyssal peridotites reported in Liang et al. (2013) are shown as orange field. Color-coded symbols are peridotites with supra-subduction zone (SSZ), mid-ocean ridge (MOR), or subcratonic (SC) affinity. Modified from Dygert and Liang (2015) 

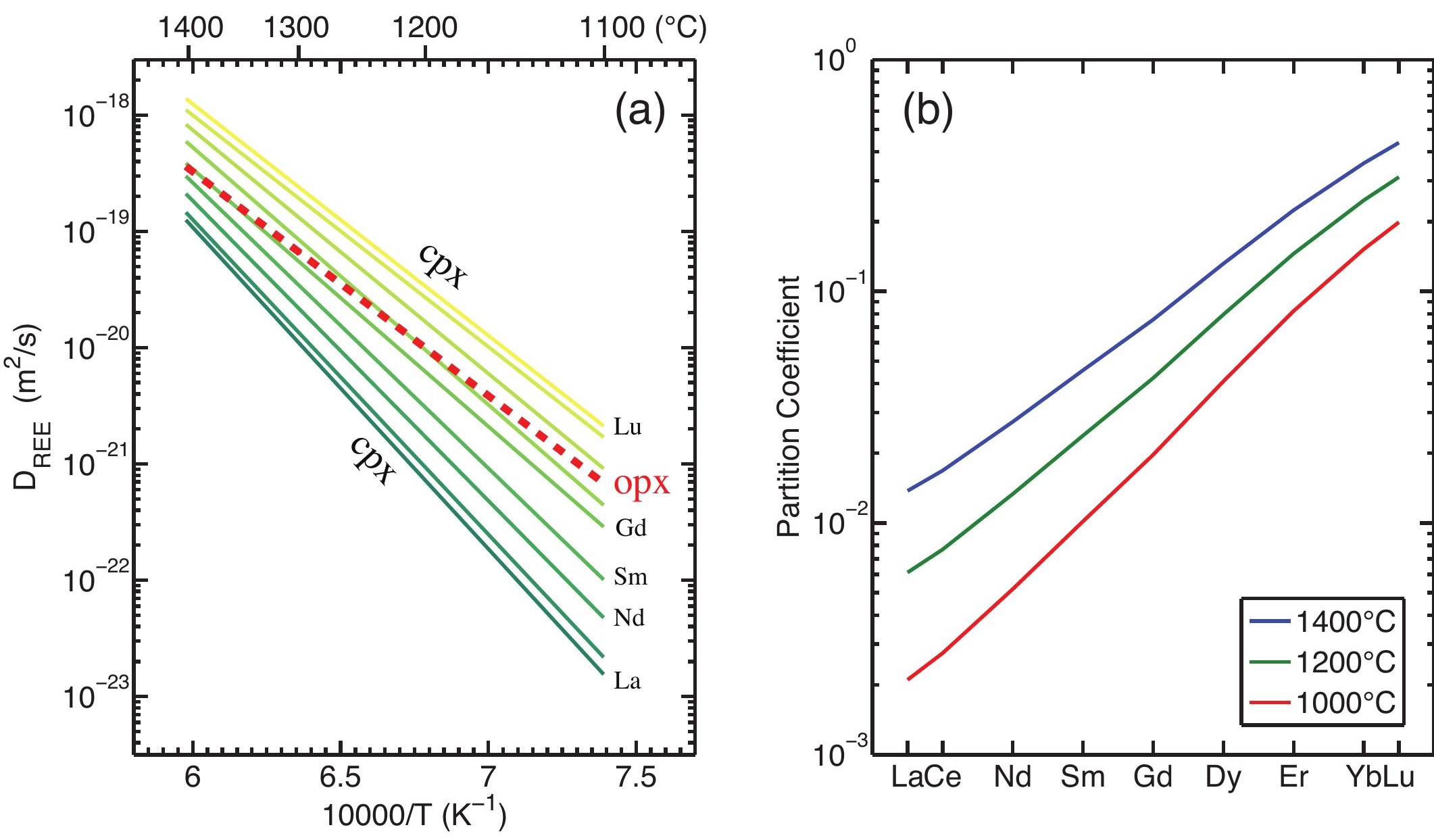
Figure 2
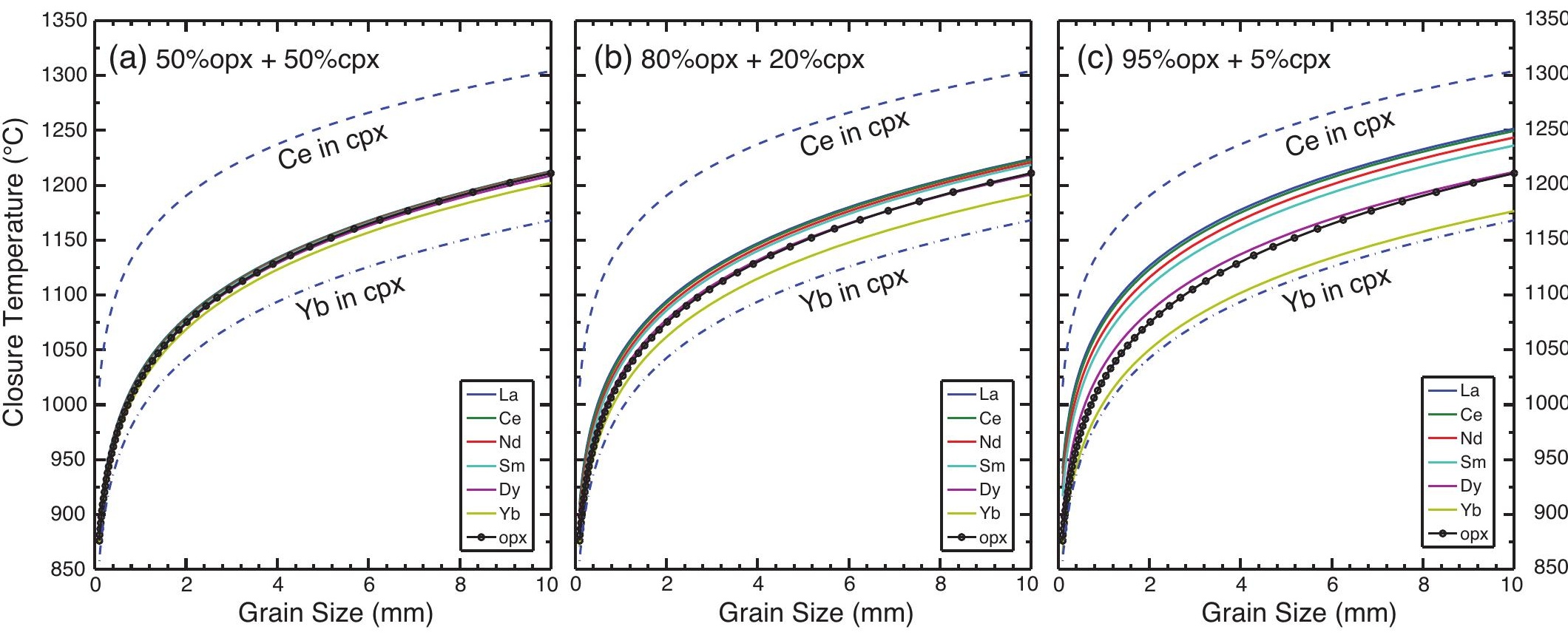

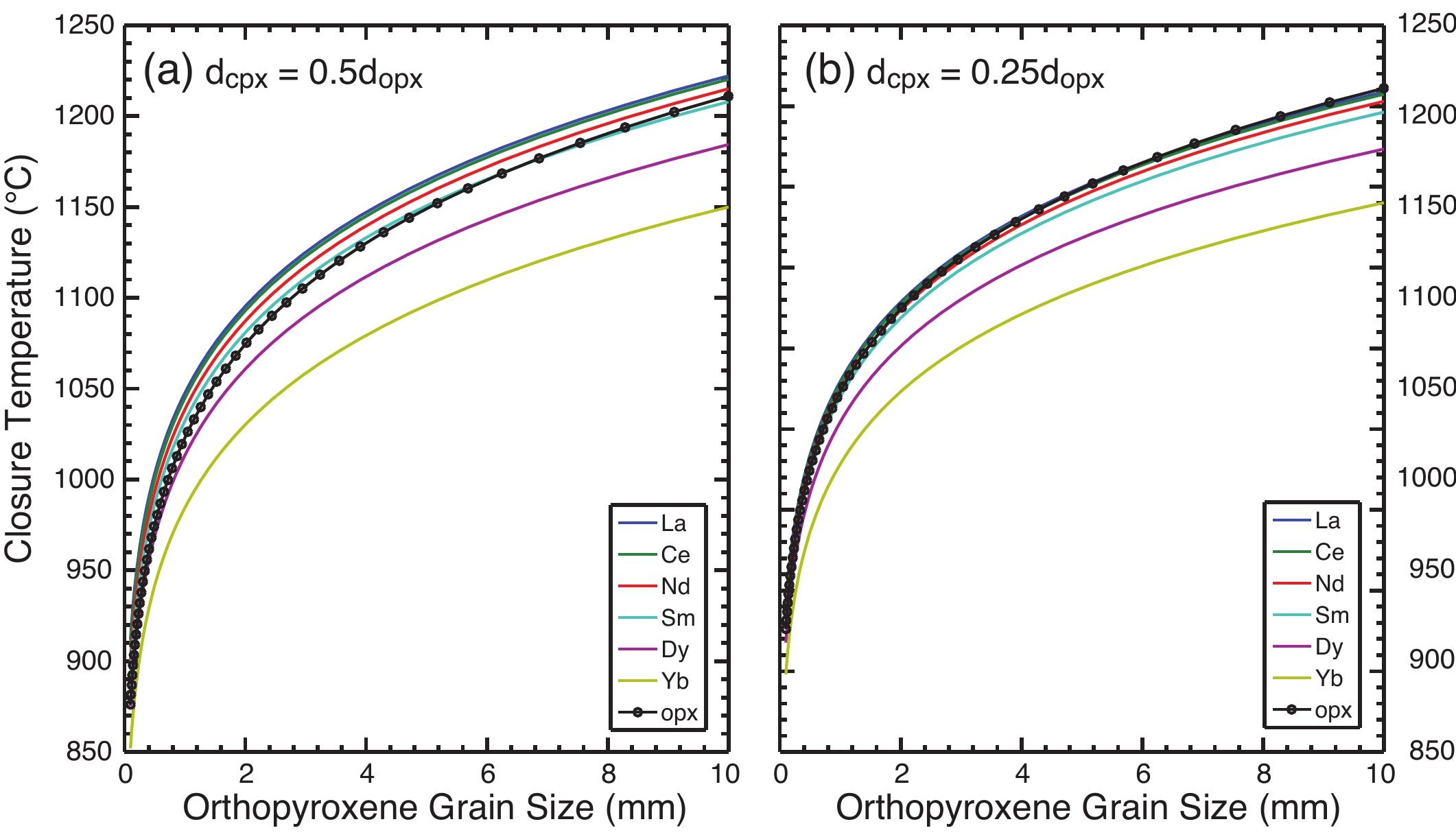


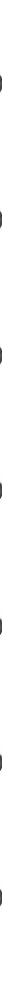




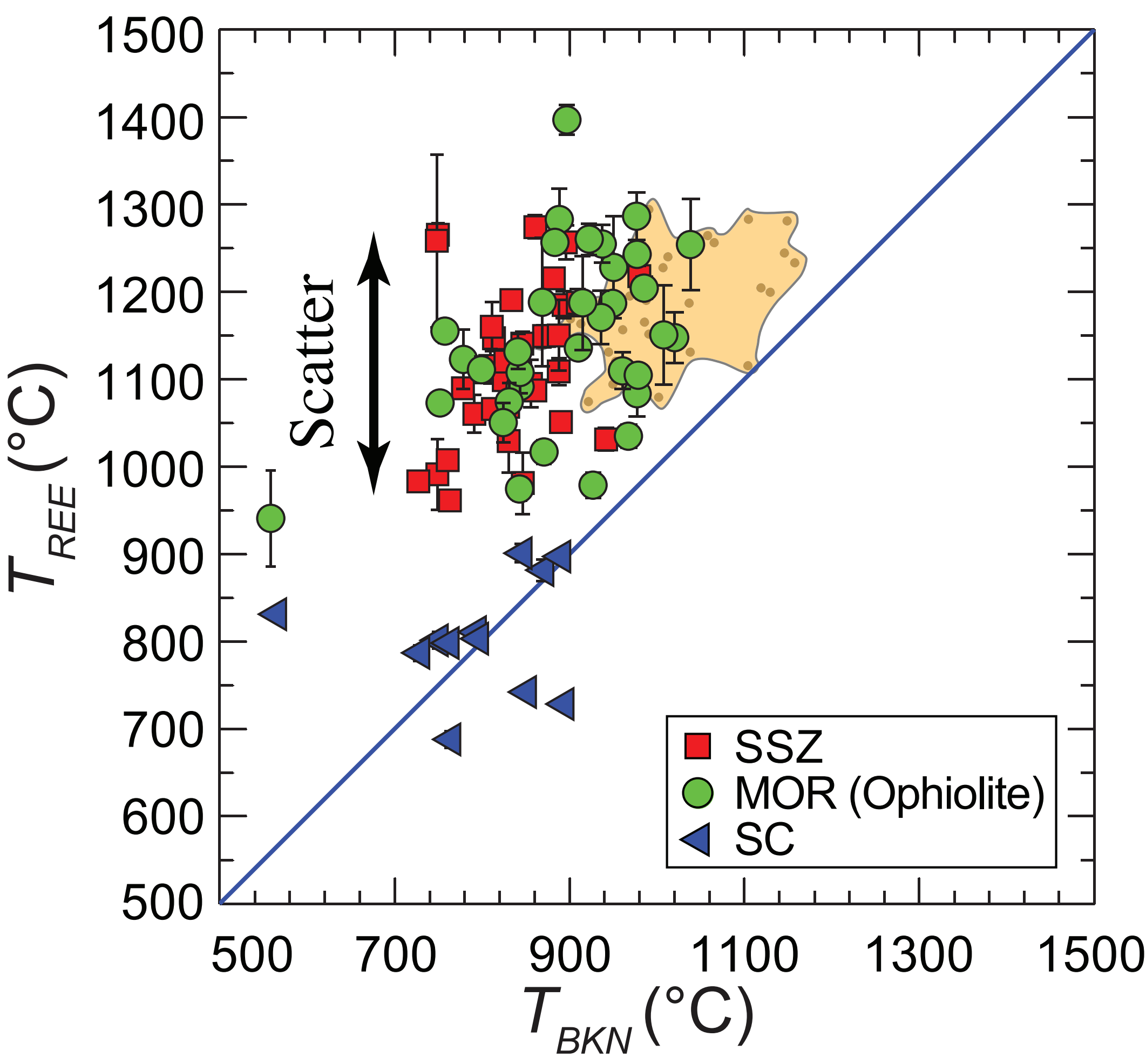

